\title{
Self-disclosed oral hygiene habits from students of Bahria University Medical and Dental College, Karachi campus
}

\author{
Rabiya Ali ${ }^{a}$, Nadia Khalid ${ }^{b}$, Fareeha ${ }^{c}$, Shireen Jawed ${ }^{d}$, Naila Masood ${ }^{e}$, Fatima Syed ${ }^{\mathrm{f}}$ \\ ${ }^{a}$ Assistant Professor, Department of Physiology, Karachi Institute of Medical Sciences (KIMS), CMH Malir Cant \\ Karachi, Pakistan. \\ ${ }^{b}$ Senior lecturer, Department of Community Health Sciences, Bahria University Medical \& Dental College Karachi, \\ Pakistan. \\ ${ }^{\mathrm{c}}$ Assistant Professor, Department of Community Health Sciences, Bahria University Medical \& Dental college \\ dProfessor, Department of Physiology, Aziz Fatima Medical and Dental College, Faisalabad. \\ eSenior Lecturer, Department of Physiology Karachi Institute of Medical Sciences, Malir Cant Karachi. \\ ${ }^{\mathrm{f}}$ Alumni, The Aga Khan University. \\ *Corresponding author: drshireenjawed@gmail.com
}

\section{ABSTRACT}

BACKGROUND \& OBJECTIVE: Dental hygiene reflects the overall health and impacts the quality of life. The present study was designed to assess knowledge, attitude, and practices regarding oral hygiene among medical and dental undergraduate students and to compare the oral hygiene habits among male and female students

METHODOLOGY: A cross-sectional study was conducted among medical and dental students of Bahria University Medical and Dental College, Karachi (BUMDC) from December 2018 to January 2019. Ethical approval was taken from the ERC committee of Bahria University Medical and Dental College (ERC/2/2018). Students ( $\mathrm{n}=332)$ of MBBS and BDS from first to final year were enrolled by non-probability convenience sampling technique. A self-structured questionnaire was used to obtain data. Percentages were determined for each response. The Chi-Square test was used to check the association of oral hygiene outcomes with respect to gender.

RESULTS: The study comprised 332 male and female students, out of which 189 (56.9\%) were dental and 143(43.1\%) were medical. The majority of students (71.4\%) were female. The mean age of participants was $20.8 \pm 1.3$ years, $44.6 \%$ used toothbrushes, $33.7 \%$ used toothbrush and floss, and $21.4 \%$ used toothbrush and miswak, $61.4 \%$ of respondents have brushed their teeth twice a day, $5.1 \%$ of respondents were reported bad smell from their teeth, $58.1 \%$ were complaining sore jaws. Dental hygiene was significantly associated with gender $(\mathrm{p} \leq 0.05)$. Females have better practices and a positive attitude toward oral hygiene.

CONCLUSION: Female students had better oral hygiene knowledge and practices with more positive attitude as compared to male counterparts.

KEYWORDS: Oral health, Oral hygiene, Knowledge, Attitude, Medical students, Dental students.

\section{INTRODUCTION}

Dental hygiene is an important element of the overall health and wellbeing of a person and reflects the positive health behavior towards dental care. Good oral health indicates disease free structures surrounding the oral cavity [1]. According to American Dental Association (ADA), "oral health is a functional, structural, aesthetic, physiologic, and psychosocial state of well-being and is essential to an individual's general health and quality of life" ${ }^{[2]}$.

Good dental hygiene shows the quality of health that makes an individual stay confident without any distress and embarrassment ${ }^{[3]}$. Poor dental health and oral disease are one of the major concerns in public health that have a significant impact socially as well as contributing the high prevalence $^{[4]}$. In addition, bad oral hygiene practices lead to poor oral health that contributes to an increase in morbidity and mortality; hence good oral hygiene practices are necessary to avoid different oral diseases ${ }^{[1]}$. Knowledge and practices regarding preventive dentistry help in maintaining good oral health ${ }^{[5]}$. A study conducted in Pakistan among medical and dental students had reported a lack of oral hygiene knowledge among dental students due to a lack of understanding regarding skills of preventive dentistry ${ }^{[5]}$.

A study conducted in America revealed an increased rate of oral disease in the emergency department since 2006 that can be prevented by basic hygiene measures ${ }^{[2]}$. Poor dental hygiene is associated with a number of factors as the use of tobacco, either chewable or smoking, stress, alcohol, and some nutritional deficiencies can 
compromise oral health, resulting in increased frequency of oral diseases ${ }^{[6]}$.

This lead to the formulation of a common risk factor approach in the prevention of oral diseases. Being professional students of dentistry, they have to focus on health education and preventive strategies, so it is very important for them to have satisfactory baseline knowledge and practices regarding oral hygiene and health ${ }^{[6]}$. However, medical students are more focused on their major subjects covering all aspects of the human body as compared to dental students who are more focused on oral health ${ }^{[7]}$. It is more important for a medical student to have optimal knowledge regarding oral health to give necessary health education of oral hygiene and refer to any dental practitioner when it will be needed ${ }^{[7]}$.

Studies have proposed a great need for health education and promotion programs to educate and motivate the population towards the proper selection of tooth cleaning devices, toothpaste and other tooth cleaning aids like dental floss / floss sticks ${ }^{[8]}$. The aim of the study was to assess knowledge, attitude, and practices regarding oral hygiene among the MBBS and BDS undergraduate students of Bahria University Medical and Dental College, Karachi campus, and to compare the oral hygiene habits among male and female students.

\section{METHODOLOGY}

A cross-sectional study was conducted among MBBS and BDS students of Bahria University Medical and Dental College, Karachi (BUMDC) from December 2018 to January 2019. Ethical approval was taken from the Ethical Review Committee of Bahria University Medical and Dental College (ERC/2/2018). The estimated sample size was 332 calculated from openepi.com. The population size was kept 1 million, design effect being 1 with confidence limit $=5$ and anticipated frequency $=50 \%$ at confidence level $95 \%$. Non-probability convenience sampling techniques was used. Medical and dental students from all years were included in the study, whereas students from allied medicine and physical therapy were excluded from the study. The medical and dental students who refused to participate were also excluded from the study.

The data collection tool was a self-structured questionnaire. The questionnaire comprised of questions related to oral hygiene was constructed by reviewing related literature. Initially, it was reviewed by senior faculty members and then validated by calculating Cronbach's Alpha(0.86) using SPSS. It was comprised of two sections; Section A has been built to assess awareness about oral hygiene using statements that are to be responded by 'Yes' or 'No'. The information regarding attitudes and practices to attain oral hygiene was explored using section $B$ on the scale-based response of participants (important, minimally important, and not important at all). The medical and dental students from the first year to the final year were approached during and after their routine group / academic sessions. The first part of the questionnaire was comprised of an informed consent form describing the purpose and benefits of the study without any risk.
It was mandatory for all students to sign it before filling questionnaire related to oral hygiene. Structured proforma was distributed among 189 BDS and 143 MBBS students. Total 332 proforma were distributed as per sample size. The confidentiality was assured to all respondents.

Data were stored and analyzed using IBM SPSS version 22.0, frequencies with percentages given for baseline characteristics of studied samples and outcomes on oral hygiene items. Pearson Chi Square test was used to check the association of oral hygiene outcomes with respect to gender. $\mathrm{p} \leq 0.05$ was considered significant. Bar charts are also used to give a graphical presentation of data.

\section{RESULTS}

Table-I report the baseline characteristics of studied samples. In the present study, there were 332 study participants, of total $189(56.9 \%)$ were BDS students and $143(43.1 \%)$ were MBBS students, $71.4 \%$ of respondents were female students, and rest were male.

Table-I: Baseline Characteristics of Studied Samples $(n=332)$.

\begin{tabular}{|c|c|c|c|}
\hline \multicolumn{2}{|c|}{ Characteristics } & \multirow{2}{*}{$\begin{array}{c}\mathbf{n} \\
143\end{array}$} & \multirow{2}{*}{$\begin{array}{c}\% \\
43.1\end{array}$} \\
\hline & Medical & & \\
\hline Course of Study & Dental students & 189 & 56.9 \\
\hline \multirow[b]{2}{*}{ Gender } & Male & 95 & 28.6 \\
\hline & Female & 237 & 71.4 \\
\hline Age (years) & Mean \pm SD & $20.8 \pm 1.3$ & \\
\hline \multirow{8}{*}{ Ethnicity } & Balochi & 5 & 1.5 \\
\hline & Hindku & 5 & 1.5 \\
\hline & Kashmiri & 10 & 3.0 \\
\hline & Memoni & 1 & 0.3 \\
\hline & Pashto & 28 & 8.4 \\
\hline & Punjabi & 127 & 38.3 \\
\hline & Sindhi & 51 & 15.4 \\
\hline & Urdu speaking & 105 & 31.6 \\
\hline \multirow[b]{2}{*}{ Living Status } & Day scholar & 177 & 53.3 \\
\hline & Hostel resident & 155 & 46.7 \\
\hline \multirow{5}{*}{ Family History } & Diabetes & 130 & 39.2 \\
\hline & Hypertension & 106 & 31.9 \\
\hline & Oral Cancer & 2 & 0.6 \\
\hline & Any other & 4 & 1.2 \\
\hline & No & 90 & 27.1 \\
\hline \multirow{4}{*}{$\begin{array}{c}\text { Your tooth cleaning } \\
\text { device }\end{array}$} & Finger & 1 & 0.3 \\
\hline & Tooth Brush & 148 & 44.6 \\
\hline & $\begin{array}{c}\text { Toothbrush and } \\
\text { Floss }\end{array}$ & 112 & 33.7 \\
\hline & $\begin{array}{l}\text { Toothbrush and } \\
\text { Miswak }\end{array}$ & 71 & 21.4 \\
\hline \multirow{3}{*}{$\begin{array}{c}\text { Frequency of teeth } \\
\text { cleaning }\end{array}$} & Once daily & 88 & 26.5 \\
\hline & Twice daily & 204 & 61.4 \\
\hline & Thrice daily & 40 & 12.0 \\
\hline History of smoking & Yes & 37 & 11.1 \\
\hline $\begin{array}{l}\text { Use of pan and } \\
\text { chalia }\end{array}$ & Yes & 3 & 0.9 \\
\hline
\end{tabular}


The mean age of participants was $20.8 \pm 1.3$ years, $38.3 \%$ were Punjabi, 31.6\% were urdu speaking, and $8.4 \%$ were Pashto, 53.3\% were day scholar, in family history $39.2 \%$ had diabetes, 31.9\% had hypertension, $44.6 \%$ used tooth brush, $33.7 \%$ used tooth brush and floss, and $21.4 \%$ used tooth brush and miswak, $61.4 \%$ said twice a day frequency of teeth cleaning, $11.1 \%$ had smoking history and $0.9 \%$ had use of pan and chalia.

Table-II: Attitude on Smell, Dental Problems and Dental visits.

\begin{tabular}{cccc}
\hline Items & n & \% \\
\hline $\begin{array}{c}\text { Has someone mentioned to } \\
\text { you about bad smell from } \\
\text { your mouth }\end{array}$ & Yes & 17 & 5.1 \\
& Dental pain & 28 & 8.4 \\
$\begin{array}{c}\text { Do you currently have any } \\
\text { of the following? }\end{array}$ & Teeth sensitivity & 52 & 15.7 \\
& Bleeding gums & 32 & 9.6 \\
& Pain in jaws & 193 & 58.1 \\
& No & 27 & 8.1 \\
If yes, is the occurrence & Seldom & 64 & 44.8 \\
& Occasionally & 51 & 35.7 \\
& Sporadic & & \\
Constantly & 1 & 0.7 \\
to the dental clinic? & No & 27 & 18.9 \\
& Last year & 52 & 15.7 \\
& Nore than a one year & 249 & 75.0 \\
What was the purpose of & Never & 31 & 9.3 \\
your last dental visit? & Planned treatment & 58 & 17.5 \\
\hline & No & 14 & 4.2 \\
\hline
\end{tabular}

Table-II gives Depicts the responses on smell. dental problems, and dental visits, Students $(5.1 \%)$ were informed by someone about the bad smell of their teeth, $58.1 \%$ had painful jaws, $44.8 \%$ showed seldom occurrence, $75 \%$ students visited dental clinic more than a one year and last visit of $61.4 \%$ individuals was for emergency care.

Table-III Results for the response of oral hygiene are presented in Table III. Strongly significant response about the dental hygiene practice and general health was $88 \%$ and daily brushing habit $(72.3 \%)$. Significant response was observed about the inter-dental cleaning $(57,8 \%)$, regular dental visits $(57.8 \%)$ and fruits and vegetables intake for oral health (61.7\%).

Non significant response was about the sugary snacks and drinks effect on teeth $(61.7 \%)$, tea and coffee effects on teeth staining $(60.7 \%)$ and tobacco and derivatives used for oral hygiene $(67.4 \%)$. Considered not significant to tobacco and derivatives used for oral hygiene.

Table-IV reports the association of dental practices with respect to gender, frequency of teeth cleaning, currently have any dental problem, its occurrence and purpose of visits to dental clinic gives significant association with gender $(\mathrm{p}<0.05)$.
Table $-\mathrm{V}$ reports the association of oral hygiene items with gender, results showed responses on dental hygiene practice and general health, and fruits and vegetable intake for oral health gives significant association with respect to gender $(\mathrm{p} \leq 0.05)$. Females had good knowledge, attitude, and practices as compared to males.

Self-disclosed oral hygiene habits from students of Bahria University Medical and Dental College, Karachi campus

\section{DISCUSSION}

Oral health is crucial for the maintenance of overall good general health. Numerous studies have reported a close association between oral diseases and several systemic conditions. Dental and systemic illness can be prevented by upkeeping the oral hygrine, which is a fundamental component of physical as well as mental well-being ${ }^{[9]}$. It also reflects the social, physiological, and psychological attributes indispensable to the quality of life ${ }^{[9]}$. Proper awareness of oral health would provide adequate care and would also be influential in preventing diseases. BDS and MBBS students should possess a high level of awareness and attitude concerning oral health care, as they are future dentists and doctors, and they will be responsible for primary health care for patient health, , so their positive attitude can be instilled among patients and the community promoting health equity. College life of the students is the best time to establish lifelong healthy habits, including oral hygiene but might often be undermined because of increased unhealthy dietary and smoking habits associated with the college setting ${ }^{[11]}$.

The positive attitude and behavior of dental and medical students can be improved during their undergraduate studies and is considered an essential factor in promoting the oral self-care habits of their patients and society in general ${ }^{[10]}$. Health professionals also play a pivotal role in providing knowledge regarding oral health and its significance to the general public ${ }^{[1,12]}$. Hence the current study was conducted to assess the status of awareness, attitude, and practices of undergraduate dental and medical students. In the present study greater responses were submitted from dental student compared to medical students reflecting their positive attitude toward oral hygiene as compared to medical students. in contrast to the current study by Rashid et al., Karachi have reported more responses from medical students as compared to dental students ${ }^{[5]}$.

Results of the current study concerning healthy practicing for oral hygiene indicates that the majority of the students have daily brushing habits, while less than half of the students recommend intra-dental cleaning using floss, indicating that dental floss use is still underestimated among students. A study from India reported the frequent use of floss reflecting good practice ${ }^{[13]}$. A recent past study conducted at Peshawar by Khalil et al., is in agreement with current findings, as the majority of their students preferred toothbrushing alone for mouth cleaning ${ }^{[14]}$. Few students of our study used miswak in addition to toothbrushing for cleaning teeth. Miswak is derived from the Salvadora persica tree (arak in Arabic), is 
Table-III: Responses on Items regarding Oral Hygiene.

\begin{tabular}{|c|c|c|c|c|}
\hline Items & $\begin{array}{l}\text { Strongly } \\
\text { significant }\end{array}$ & $\begin{array}{l}\text { Significant } \\
\text { n }(\%)\end{array}$ & $\begin{array}{c}\text { Minimally } \\
\text { significant } \\
\text { n (\%) }\end{array}$ & $\begin{array}{c}\text { Not } \\
\text { significant } \\
\text { n (\%) }\end{array}$ \\
\hline Dental hygiene practice and general health & 292(88) & $33(9.9)$ & $7(2.1)$ & - \\
\hline Daily brushing routine & $240(72.3)$ & $88(26.5)$ & $4(1.2)$ & - \\
\hline Inter-dental cleaning such as flossing & $95(28.6)$ & $190(57.2)$ & $41(12.3)$ & $6(1.8)$ \\
\hline Regular dental visits & $77(23.2)$ & $192(57.8)$ & $40(12)$ & $23(6.9)$ \\
\hline Fruits and vegetables intake for oral health & $99(29.8)$ & 205(61.7) & $25(7.5)$ & $3(0.9)$ \\
\hline Sugary snacks and drinks effects teeth & $50(15.1)$ & $48(14.5)$ & $20(6)$ & $213(64.4)$ \\
\hline Tea and coffee effects on teeth staining & $60(18.1)$ & $52(15.7)$ & $18(5.4)$ & $201(60.7)$ \\
\hline $\begin{array}{c}\text { Tobacco and derivatives use (pan, chalia, and other such items) on } \\
\text { oral health }\end{array}$ & $80(24.2)$ & $18(5.4)$ & $10(3)$ & $223(67.4)$ \\
\hline
\end{tabular}

Table-IV: Association of Dental Practices with respect to gender.

\begin{tabular}{|c|c|c|c|c|}
\hline Items & & & & \multirow[b]{2}{*}{ p-value } \\
\hline \multirow{4}{*}{ Your tooth cleaning device } & & Male & Female & \\
\hline & Tooth Brush & $43(45.3 \%)$ & $105(44.3 \%)$ & \\
\hline & Tooth brush and Floss & $32(33.7 \%)$ & $80(33.8 \%)$ & \\
\hline & Tooth brush and Miswak & $19(20.0 \%)$ & $52(21.9 \%)$ & \\
\hline \multirow[t]{3}{*}{ Frequency of teeth cleaning } & Once daily & $35(36.8 \%)$ & $53(22.4 \%)$ & \multirow{3}{*}{$<0.01^{*}$} \\
\hline & Twice daily & $56(58.9 \%)$ & $148(62.4 \%)$ & \\
\hline & Thrice daily & $4(4.2 \%)$ & $36(15.2 \%)$ & \\
\hline \multirow{5}{*}{ Do you currently have any of the following? } & Dental pain & $10(10.5 \%)$ & $18(7.6 \%)$ & \multirow{5}{*}{$<0.01 *$} \\
\hline & Teeth sensitivity & $15(15.8 \%)$ & $37(15.6 \%)$ & \\
\hline & Bleeding gingiva & $2(2.1 \%)$ & $30(12.7 \%)$ & \\
\hline & painfuljaws & $55(57.9 \%)$ & $138(58.2 \%)$ & \\
\hline & No & $13(13.7 \%)$ & $14(5.9 \%)$ & \\
\hline \multirow{4}{*}{ If yes, is the occurrence } & Seldom & $13(29.5 \%)$ & $51(51.5 \%)$ & \multirow{4}{*}{$0.02 *$} \\
\hline & Occasionally Sporadic & $17(38.6 \%)$ & $34(34.3 \%)$ & \\
\hline & Constantly & $1(2.3 \%)$ & $0(0.0 \%)$ & \\
\hline & No & $13(29.5 \%)$ & $14(14.1 \%)$ & \\
\hline \multirow{3}{*}{$\begin{array}{c}\text { When was your last visit to the dental } \\
\text { clinic? }\end{array}$} & Last year & $13(13.7 \%)$ & $39(16.5 \%)$ & \multirow{3}{*}{0.21} \\
\hline & more than a year ago & $69(72.6 \%)$ & $180(75.9 \%)$ & \\
\hline & Never & $13(13.7 \%)$ & $18(7.6 \%)$ & \\
\hline \multirow{4}{*}{$\begin{array}{l}\text { What was the purpose of your last dental } \\
\text { visit? }\end{array}$} & Emergency care & $56(58.9 \%)$ & $148(62.4 \%)$ & \multirow{4}{*}{$0.03 *$} \\
\hline & Routine care & $10(10.5 \%)$ & $46(19.4 \%)$ & \\
\hline & Planned treatment & $22(23.2 \%)$ & $36(15.2 \%)$ & \\
\hline & No & $7(7.4 \%)$ & $7(3.0 \%)$ & \\
\hline
\end{tabular}

\section{${ }^{*} \mathrm{p} \leq \mathbf{0 . 0 5}$ was considered significant using the Pearson Chi-Square test.}

a traditional tooth-cleaning twig alternative to the modern toothbrush, and offers comparatively stronger chemical and mechanical cleaning of oral tissues than a toothbrush. Current results are in agreement with Malaysian study that reported frequent use of miswak among their study participants. However, they documented comparatively higher values of miswak users than the current study ${ }^{[15]}$.

Participants of the current study understood the importance of a healthy diet in dental care, and more than half of them agreed to have a positive impact of fruits and vegetable consumption on oral health. However, half of the students also have a misconception and they believed that sugary snacks and drinks would not harm teeth, more ever they also misbelieved that use of coffee, tea and tobacco smoking have no impact on staining teethes or any harmful effect on oral hygiene and health. In contrast to our results, a previous study conducted in Karachi reported a lack of awareness concerning the harmful effects of cigarettes consumption among small percentages of students and the majority of students to be aware of the hazardous impact of smoking on general body health ${ }^{[5]}$. Current results are also justified by a 
Oral hygiene in Medical and Dental students

Table-V: Association of Oral Hygiene Items with Gender.

\begin{tabular}{|c|c|c|c|c|}
\hline Items & \multicolumn{3}{|c|}{ Gender } & \multirow{4}{*}{ p-value } \\
\hline \multirow{4}{*}{ Dental hygiene practice and general health } & & $\begin{array}{l}\text { Male } \\
\mathbf{n}(\%)\end{array}$ & $\begin{array}{c}\text { Female } \\
\text { n(\%) }\end{array}$ & \\
\hline & Strongly significant & $85(89.5 \%)$ & $207(87.3 \%)$ & \\
\hline & Significant & $5(5.3 \%)$ & $28(11.8 \%)$ & \\
\hline & Minimally significant & $5(5.3 \%)$ & $2(0.8 \%)$ & \\
\hline \multirow{4}{*}{ Daily brushing routine } & Strongly significant & $67(70.5 \%)$ & $173(73.0 \%)$ & \\
\hline & Significant & $26(27.4 \%)$ & $62(26.2 \%)$ & 0.61 \\
\hline & Minimally significant & $2(2.1 \%)$ & $2(0.8 \%)$ & \\
\hline & Strongly significant & $19(20.0 \%)$ & $76(32.1 \%)$ & \\
\hline \multirow{3}{*}{ Interdental cleaning such as flossing } & Significant & $61(64.2 \%)$ & $129(54.4 \%)$ & \\
\hline & Minimally significant & $12(12.6 \%)$ & $29(12.2 \%)$ & \\
\hline & Not significant & $3(3.2 \%)$ & $3(1.3 \%)$ & 0.11 \\
\hline \multirow{4}{*}{ Regular dental visits } & Strongly significant & $17(17.9 \%)$ & $60(25.3 \%)$ & \\
\hline & Significant & $55(57.9 \%)$ & $137(57.8 \%)$ & \\
\hline & Minimally significant & $14(14.7 \%)$ & $26(11.0 \%)$ & \\
\hline & Not significant & $9(9.5 \%)$ & $14(5.9 \%)$ & 0.30 \\
\hline \multirow{4}{*}{ Fruits and vegetables intake for oral health } & Strongly significant & $18(18.9 \%)$ & $81(34.2 \%)$ & \\
\hline & Significant & $63(66.3 \%)$ & $142(59.9 \%)$ & \\
\hline & Minimally significant & $13(13.7 \%)$ & $12(5.1 \%)$ & \\
\hline & Not significant & $1(1.1 \%)$ & $2(0.8 \%)$ & $<0.01 *$ \\
\hline \multirow{4}{*}{ Sugary snacks and drinks effects on teeth } & Strongly significant & $14(14.7 \%)$ & $36(15.3 \%)$ & \\
\hline & Significant & $16(16.8 \%)$ & $32(13.6 \%)$ & \\
\hline & Minimally significant & $3(3.2 \%)$ & $17(7.2 \%)$ & \\
\hline & Not significant & $62(65.3 \%)$ & $151(64.0 \%)$ & 0.50 \\
\hline \multirow[b]{2}{*}{ Tea and coffee effects on teeth staining } & Strongly significant & $20(21.1 \%)$ & $40(16.9 \%)$ & \multirow[b]{2}{*}{0.055} \\
\hline & $\begin{array}{c}\text { Significant } \\
\text { Minimally significant } \\
\text { Not significant }\end{array}$ & $\begin{array}{l}21(22.1 \%) \\
2(2.1 \%) \\
52(54.7 \%)\end{array}$ & $\begin{array}{c}31(13.1 \%) \\
16(6.8 \%) \\
149(63.1 \%)\end{array}$ & \\
\hline $\begin{array}{l}\text { Tobacco and derivatives use, (pan, chalia and } \\
\text { other such items) on oral health }\end{array}$ & $\begin{array}{l}\text { Strongly significant } \\
\text { Significant } \\
\text { Minimally significant } \\
\text { Not significant }\end{array}$ & $\begin{array}{l}29(30.5 \%) \\
7(7.4 \%) \\
4(4.2 \%) \\
55(57.9 \%)\end{array}$ & $\begin{array}{c}51(21.6 \%) \\
11(4.7 \%) \\
6(2.5 \%) \\
168(71.2 \%)\end{array}$ & 0.13 \\
\hline
\end{tabular}

\section{*p $\leq \mathbf{0 . 0 5}$ was considered significant using Pearson Chi Square test}

previous study by Alomari et al. that reported healthy dental behaviors in nonsmokers than smokers. This aforementioned study has reported worse dental health attitudes in smokers as they were less bothered about the health of their gums, the color of their teeth, and bad order in a breath ${ }^{[16]}$.

The current research reports the association of knowledge and dental practices with respect to gender. Frequency of teeth cleaning, the occurrence of dental problems and visits to dental clinics gives a significant association with gender $(\mathrm{p}<0.05)$.

The current research evidenced that female student were better than their male counterparts in terms of dental knowledge and practices. This was in line with a previous study conducted in Karachi, documenting females were more conscious about oral hygiene than males ${ }^{[10]}$. Similar findings have been reported by Al Tayar et al., and Gopikrishna et al studies ${ }^{[15,17]}$. Contrary to current results, no differences among male and female knowledge, attitude and practice concerning dental hygiene were reported from Kerala, India ${ }^{[13]}$.

The current study reports the significant difference in consuming healthy diet including intake of fruits and vegetable for better oral health among the gender $(\mathrm{p}<0.05)$ we noticed that the females have better practices and attitude and consumes more fruits and vegetables for their general as well as oral health. In line with our study, a previous study conducted by Naseem et al at documented that females students were more conscious about oral hygiene than males students, that's why they consumed fewer soft drinks and a more healthy diet than males ${ }^{[2]}$.

The positive oral health attitudes of female students are the result of numerous factors, including the importance of 
appearance, consciousness about health maintenance, and fitness ${ }^{[2]}$. Previous studies conducted worldwide showed females were more aware of correct brushing techniques and they were more anxious about having bad breath as compared to males ${ }^{[2]}$. There is a terrible requisite to spread knowledge about correct teeth cleaning techniques as poor oral hygiene habits can have an injurious effect on the general wellbeing and excellence of life of people ${ }^{[2]}$. Healthy habits are fostered by a positive attitude and awareness that is crucial to improve resource efficiency and healthcare standards.

In the current study, a Significantly majority of male and female brushed their teeth twice daily while few male and females brushed their teeth thrice daily hence indicating better oral hygiene measures adopted by female students. Results of Rashid et al study from Karachi is in accordance with our results, documenting females were more frequent with brushing as compared to males ${ }^{[10]}$. Neeraja et al. reported that the majority of the dental students brushed their teeth twice daily ${ }^{[18]}$. Almost equal numbers of male and females in our study used miswak in addition to the toothbrush, in contrast to current results, Al-Tayar et al reported the frequent use of miswak among males as compared to females ${ }^{[15]}$. In the current study, female students were reported to frequent teeth sensitivity, bleeding gingiva, and dental pain compared to male counterparts despite having a better understanding and knowledge of dental practice and oral hygiene habits. On the contrary to current findings, a study performed by Kaul et al in India analyzing the awareness and practicing of MBBS and BDS students reported the occurrence of these symptoms more commonly in male students ${ }^{[19]}$.

We further reported that females are mostly aware to visit the dental clinics due to emergency care routine checkups and planned treatment. Our results are endorsed by various studies conducted in Jordan and Malaysia that reported that male students were reluctant and visited the dentist only when they had severe dental pain ${ }^{[10,15]}$. Al tayar et al also believed that toothache was the main driving factor for students to visit the dentist ${ }^{[15]}$. Current results reveal that most dental students visited the dentist once in their lifetime, inconsistent with this finding, and previous studies reported that a lesser number of students visited the dental clinic for a checkup in routine ${ }^{[1,18]}$. It is important to provide the necessary oral health interventions and dental education to college students to make them aware of the importance of oral hygiene to maintain their lifelong health behaviors and self-confidence.

\section{CONCLUSION}

The oral health knowledge of female medical and dental students was better compared to male students. Female students had better oral health practices and took better care of their teeth than male students.

\section{FUTURE PERSPECTIVES:}

Further emphasis on oral health is necessary for undergraduate training to improve oral health knowledge, attitude, and practice among the male students. These students, who are the future providers of dental and medical care, will act as role models for oral health education among individuals and the community at large.

ACKNOWLEDGEMENTS: We acknowledged with thanks to dr Rehana Rehman for her guidance and support. We are also grateful to all students for their cooperation and helps us in completing data collection.

\section{CONFLICTS OF INTEREST: None.}

GRANT SUPPORT \& FINANCIAL DISCLOSURE: None.

\section{REFERENCES:}

1. Kumar H, Behura SS, Ramachandra S, Nishat R, Dash $\mathrm{KC}$, Mohiddin G. Oral health knowledge, attitude, and practices among dental and medical students in Eastern India-A comparative study. Journal of International Society of Preventive \& Community Dentistry. 2017;7(1):58-63. Doi: 10.4103/jispcd.JISPCD_30_17

2. Naseem S, Fatima SH, Ghazanfar H, Haq S, Khan NA, Mehmood M. Oral hygiene practices and teeth cleaning techniques among medical students. Cureus. 2017;9(7): e1487. Doi: 10.7759/cureus. 1487

3. Almoteb MM, Alalyani SS, Gowdar IM, Penumatsa NV, Siddiqui MA, Sharanesha RB. Oral hygiene status and practices among health-care workers: A crosssectional study. Journal of International Oral Health. 2019;11(5):268-273. Doi: 10.4103/jioh.jioh_315_18.

4. Gualie YT, Tayachew AT. Assessment of knowledge, attitude, and practice toward oral hygiene among governmental secondary school students in Debre Tabor Town, Amhara Region, North Central Ethiopia 2018: Institutional-based cross-sectional survey. International Journal of Oral Health Sciences. 2018;8(2):92-98. Doi: 10.4103/ijohs.ijohs_37_18

5. Rashid MS, Ali BI, Bashir S, Haider BS, Hafeez N, Aslam MA. Attitude Towards Own Oral Health and Hygiene: A Survey of Medical and Dental Students of Karachi, Pakistan. Journal of Pakistan Dental Association. 2016;25(02):53-58.

6. Kaur S, Kaur B, Ahluwalia SS. Oral health knowledge, attitude and practices amongst health professionals in Ludhiana, India. Dentistry. 2015;5(7):1. Doi:10.4172/2161-1122.1000315.

7. Kumar H, Behura SS, Ramachandra S, Nishat R, Dash $\mathrm{KC}$, Mohiddin G. Oral health knowledge, attitude, and practices among dental and medical students in Eastern India-A comparative study. Journal of International Society of Preventive \& Community Dentistry. 2017;7(1):58-63. Doi: 10.4103/jispcd.JISPCD_30_17

8. Bangash MFK, Jamroz Khan AH. Oral hygiene practice and awareness among Pakistanis in Riyadh, Saudi Arabia, Pak. Oral Dental Journal. 2013;33(2):350-353. 
9. Desai A, Kumar H, Nishat R, Aspalli S, Nagappa G. Comparative evaluation of awareness of link between oral and systemic health among undergraduate dental and medical students. European Journal of Molecular \& Clinical Medicine. 2021;08(1):602-609.

10. Al-Wesabi AA, Abdelgawad F, Sasahara H, El Motayam $\mathrm{K}$. Oral health knowledge, attitude and behaviour of dental students in a private university. Biodiversity Data Journal. 2019;5(1):1-5. Doi: 10.1038/s41405-0190024-X

11. Crabtree R, Kirk A, Moore M, Abraham S. Oral health behaviors and perceptions among college students. The Health Care Manager. 2016;35(4):350-360.

12. Maharani DA, Ariella S, Syafaaturrachma ID, Wardhany II, Bahar A, Zhang S, et al. Attitude toward and awareness of medical-dental collaboration among medical and dental students in a university in Indonesia. BMC Oral Health. 2019;19(1):1-7. Doi.10.1186/ s12903-019-0848-8

13. Ahamed S, Moyin S, Punathil S, Patil NA, Kale VT, Pawar G. Evaluation of the oral health knowledge, attitude and behavior of the preclinical and clinical dental students. Journal of International Oral Health. 2015;7(6):65-70.

14. Khalil ZR, HameedA, Khan A, Zia M, Arbab KN. Oral hygiene practices among dental students of peshawar city a comparative study. Journal of Khyber College of Dentistry. 2019; 9(3): 1-8. Doi: https://doi. org/10.33279/2307-3934.2019.91225

15. Al-Tayar BA, Ahmad A, Sinor MZ, Harun MH. Oral health knowledge, attitude, and practices among Yemeni school students. Journal of International Oral Health. 2019;11(1):15-20

16. Alomari Q, Barrieshi-Nusair K, Said K. Smoking prevalence and its effect on dental health attitudes and behavior among dental students. Medical Principles and Practice. 2006;15(3):195-199. Doi: 10.1159/000092181

17. Gopikrishna V, Bhaskar NN, Kulkarni SB, Jacob J, Sourabha KG. Knowledge, Attitude, and Practices of oral hygiene among college students in Bengaluru city. Journal of Indian Association of Public Health Dentistry. 2016;14(1):75-79.

18. Neeraja R, Kayalvizhi G, Sangeetha P. Oral health attitudes and behavior among a group of dental students in Bangalore, India. European Journal of Dentistry. 2011;5(02):163-167.

19. Kaul V, Gupta N, Rathore PK, Kaul N. A comparative evaluation of oral hygiene practİces and habIts among medical \& dental students in ghaziabad district. Medico Research Chronicles. 2018;5(6):544-55.

\section{Author's Contribution:}

Rabiya Ali: Study design and concept, manuscript writing revise and approve the article.

Nadia Khalid: Study design, data collection, manuscript writing, revise and approve the article.

Fareeha: Study design, data collection, data analysis, interpretation of results, writing of results, critically revise the manuscript.

Shireen Jawed: Data analysis, interpretation of results, critically revise the manuscript for all intellectual content and make all necessary revision in manuscript. Check and correct all the references carefully approve the article.

Naila Masood: Study design, help in writing manuscript and revise and approve the article.

Fatima Syed: Study design and data collection, review and approve the article.

Submitted for Publication:24-01-2021 Accepted after revision: 19-09-2021 